\title{
Potential contribution of local air quality management to environmental justice in England
}

\author{
I. Gegisian, M. Grey, J. W. S. Longhurst \& J. G. Irwin \\ University of the West of England, Bristol, UK
}

\begin{abstract}
The United Kingdom has a well-developed system of local air quality management established to combat air quality problems at a local level. In England air quality management areas tend to cover areas of greater social deprivation, and action plans developed to address poor air quality provide an opportunity to take account of environmental justice. However, this is not explicitly required by Government guidance and evidence to date suggests that the opportunity has not been realised. Many measures in current air quality action plans are not specific to air quality. This holds out the potential for greater integration of air quality measures with other local strategies, most notably local transport plans, which take greater account of environmental justice issues. Although not primarily intended to improve air quality or address environmental inequality, the London Congestion Charge provides evidence of the potential of this type of measure.
\end{abstract}

Keywords: air pollution, deprivation, environmental justice, local air quality management.

\section{Introduction}

Environmental justice (EJ) may be defined as the equitable treatment of all people in the development and implementation of environmental policies, regardless of race, creed, income and social class. While the concept emerged in the United States of America in response to concerns regarding race [1], in the United Kingdom concern has focussed more generally on deprivation. Research by the Environment Agency [2] found a strong relationship between air quality and deprivation in England. Such relationships have added significance as 
deprived individuals may be more susceptible to the adverse health effects of air pollution due to their relative disadvantage or predisposing health conditions or behaviours [3]. One review has found that in five out of six cohort studies stronger associations were observed between mortality and exposure to air pollution among lower socioeconomic groups, although few of the results were statistically significant and the work revealed the difficulties in determining which characteristics of deprivation influenced the association [4].

The United Kingdom has a well-developed system of local air quality management established to combat air quality problems at a local level. The statutory framework was established in the Environment Act 1995 [5] which sets air quality objectives and standards for eight pollutants: benzene, 1,3 butadiene, carbon monoxide, nitrogen dioxide, lead, particles as $\mathrm{PM}_{10}$, sulphur dioxide and ozone, although ozone is not included in local air quality management. If air quality objectives are, or are likely to be, exceeded, a local authority (LA) must define and declare an Air Quality Management Area (AQMA) and develop an Air Quality Action Plan (AQAP) to address the exceedances. The system and its implementation have been analysed in a number of publications eg Longhurst et al. [6]. In theory, the approach provides an opportunity to address issues of environmental justice when developing action plans. The research described here used a range of methods to address two questions. Firstly, it investigated equity in exposure to air pollution by using the presence or absence of an air quality management area as an indicator of exposure to pollution. Secondly, it examined the extent to which local authorities are taking account of social deprivation in developing their AQAPs.

\section{Methodology}

Qualitative and quantitative analytical methods were used together with GIS for visualisation and spatial analyses [7]. The practices of LAs in developing their AQAPs were assessed in three ways: an appraisal of the published action plan, a questionnaire to the authorities and a small number of case study interviews of officials. The appraisal used a checklist to collect information on the compilation of the AQAP and, in particular, any measures and mechanisms used to take account of EJ, or social issues in general. The questionnaire survey was undertaken to verify the appraisal, collect more up to date information on progress with the AQAP and assist in the selection of case studies. The case studies provided an opportunity to address themes emerging from the questionnaire in more detail and collect personal perspectives on the challenges of accommodating EJ issues within the local air quality management process.

The Index of Multiple Deprivation (IMD) is the English index for computing deprivation on a small area scale. The index consists of a number of parameters that express elements of deprivation and is divided into seven domains: income, employment, health deprivation and disability, education, skills and training, barriers and housing, crime and the living environment. Each of these domains is constructed of a number of indicators. A description of how these indices and domains are compiled and statistically manipulated has been published [8]. The 
indices were used as the measure of social deprivation in this study. Spatially they are based on the lower layer super output areas (SOA) from the UK census. These are areas with a minimum population of 1000 and a mean of about 1500 people based on postcode units.

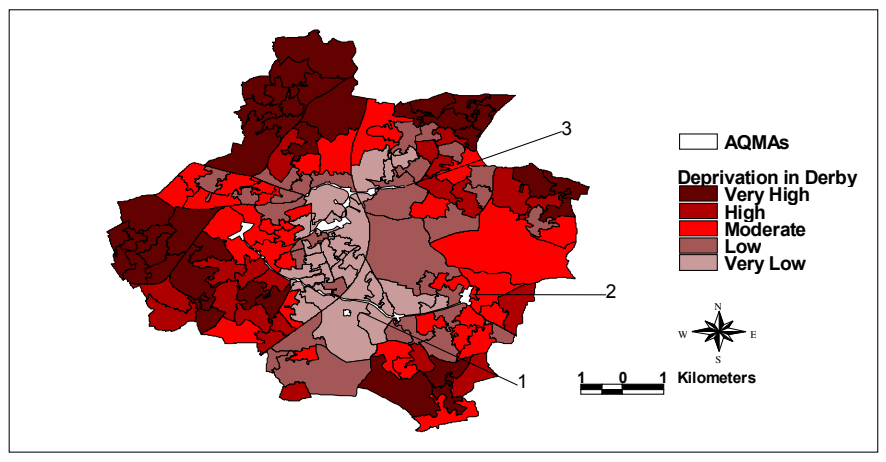

Figure 1: Areas of deprivation and three AQMAs in Derby.

An example map showing deprivation by SOA with the AQMAs superimposed is shown in Figure 1.

\section{Results}

\subsection{Deprivation results}

An analysis of deprivation in AQMAs was conducted in order establish whether areas with elevated levels of pollution also suffer from high deprivation. Figure 2 considers the SOAs within AQMAs. The level of deprivation is predominately between the first and fourth deciles with over one third of the SOAs in the two most deprived deciles, compared with $10 \%$ in the two least deprived deciles. In Table 1 the distribution of deprivation in AQMAs is compared with the overall level of deprivation. The more deprived an SOA is, the more likely it is to be located in an AQMA.

The general conclusion can be drawn that AQMAs are more likely to have above average levels of deprivation rather than lower. Based on the average IMD score at district level, the North East and North West of England have the largest numbers of their districts in the most deprived deciles where 1 is the most deprived.

\subsection{Taking account of deprivation}

The second element of the research was to examine the extent to which LAs were taking account of deprivation in developing their action plans. The 


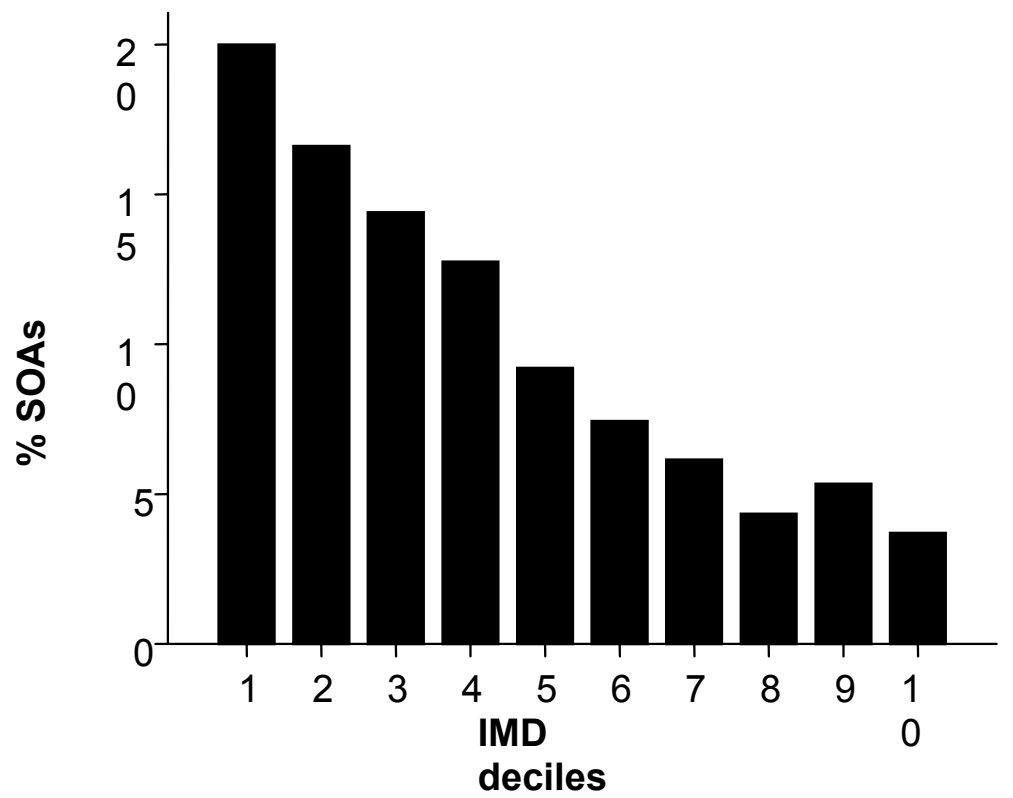

Figure 2: Distribution of deciles of deprivation in AQMAs (non whole boroughs) based on their associated SOAs $(n=2485)$.

Table 1: Distribution of deprivation in AQMAs compared to overall deprivation in Las.

\begin{tabular}{|l|l|l|l|}
\hline $\begin{array}{l}\text { Deciles of } \\
\text { deprivation }\end{array}$ & $\begin{array}{l}\text { No of SOAs in } \\
\text { AQMAs }\end{array}$ & $\begin{array}{l}\text { Total no of SOAs } \\
\text { in associated LAs }\end{array}$ & $\%$ \\
\hline 1 & 497 & 1479 & 34 \\
\hline 2 & 413 & 1274 & 32 \\
\hline 3 & 358 & 1197 & 30 \\
\hline 4 & 317 & 1115 & 28 \\
\hline 5 & 229 & 1021 & 22 \\
\hline 6 & 185 & 982 & 19 \\
\hline 7 & 152 & 971 & 16 \\
\hline 8 & 108 & 906 & 12 \\
\hline 9 & 133 & 968 & 14 \\
\hline 10 & 92 & 946 & 10 \\
\hline
\end{tabular}

questionnaire survey which was sent to local authorities achieved a response rate of over $50 \%$ and identified 116 authorities that had produced AQAPs. Each plan was then examined to extract data on how it was prepared, the measures that were included and the extent to which EJ considerations had been taken into account through public participation or involvement of relevant bodies, as well as the direct use of social data, including deprivation. 


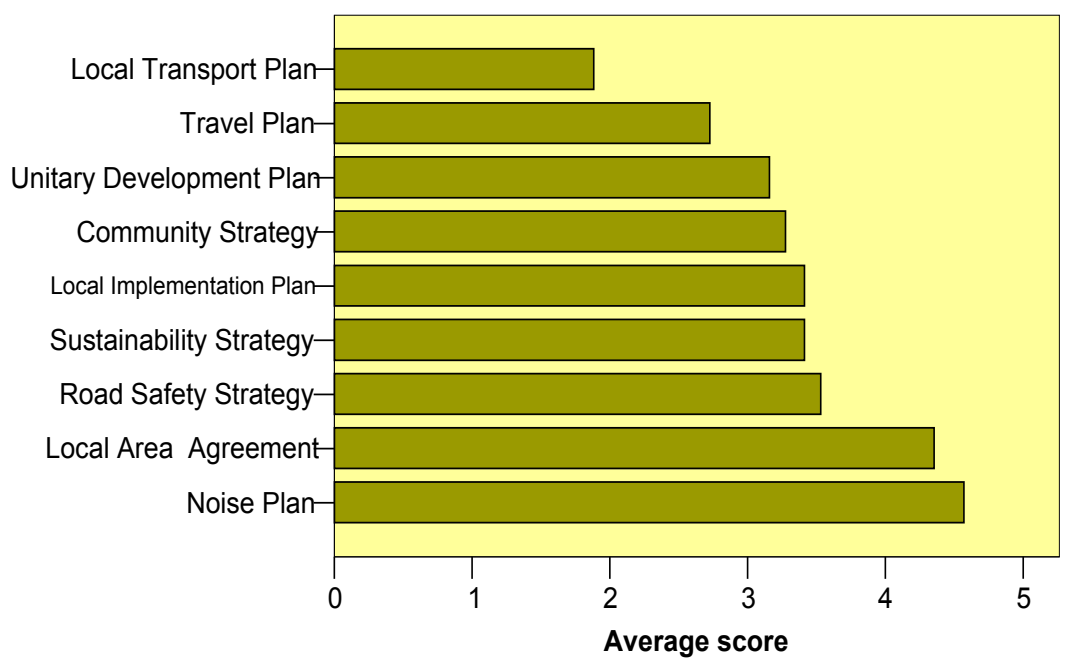

Figure 3: Internal strategies; the mean score for each option is shown where 1 is a highly considered strategy and 5 is a strategy that is not considered $(n=67)$.

The measures included in the plans were mainly transport related (Figure 3). The plans were also found to be flexible with consideration of educational and public awareness measures. These are the measures that most environmental health departments, responsible for LAQM, can actually implement. In line with government guidance these measures were prioritised according to their cost effectiveness, timetable and responsibility.

Although the integration of AQAPs with Local Transport Plans (LTP) is becoming widespread, about two-thirds of respondents found that this had made the process more complex. Results on internal collaboration indicated that, consistent with the strategies identified as important, transport and planning departments are most closely involved.

External organisations identified as relevant included County Councils, the Highways Agency and neighbouring authorities (Figure 4). In most cases the AQAPs included a list of consultees but did not provide information on their level of involvement. According to the appraisal, authorities also distributed their plan to many different organisations, the most common being the Primary Care Trusts or Health Authorities.

But the types of measures and the way they were reported in the AQAPs meant it was very difficult to assess their respective contribution. A classification of measures according to their origin and prospect of implementation revealed that the majority were not AQAP specific.

An EJ score was attributed to each plan [7]. This took account of evidence such as: specific statements relating to social impacts, consideration of relevant strategies, liaison with relevant local authority departments, public participation 
and the use of methods for measuring social factors. The EJ scores show that the majority of plans were deemed limited or failing with only 12 out of the 116 LAs achieving an excellent or good score (Figure 5). The results indicated that social impacts are not explicitly considered in the process.

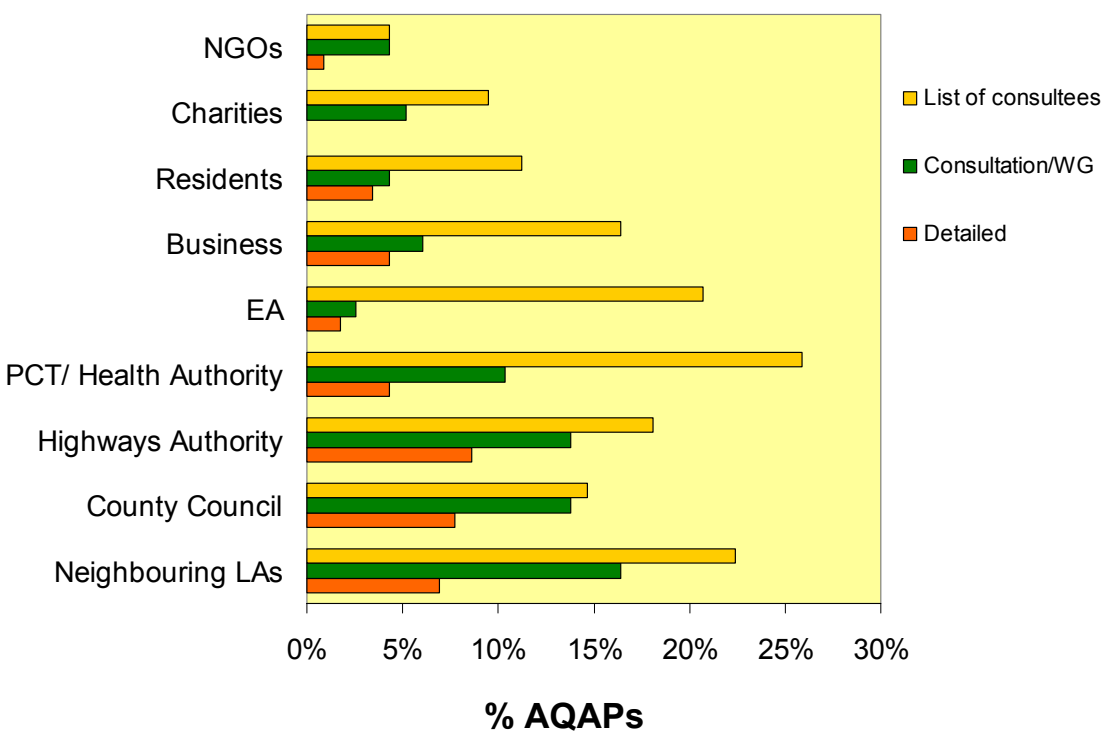

Figure 4: $\quad$ Involvement of external organisations (no of AQAPs $=116$ ).

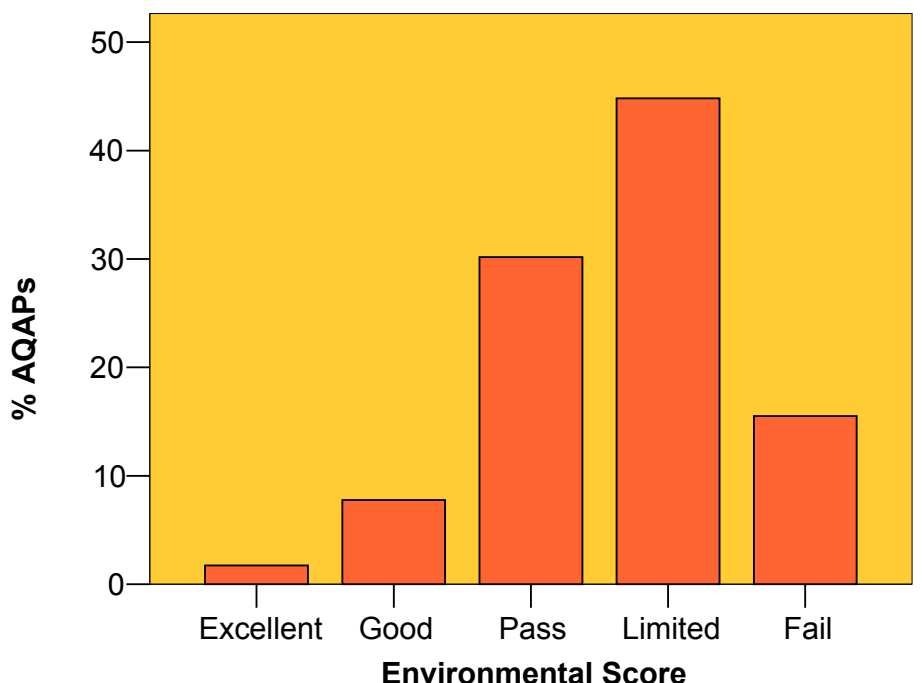

Figure 5: $\quad$ The Environmental Justice score for AQAPs $(\mathrm{n}=116)$. 
The case studies examined different types of local authorities in terms of their organisation, geographical region and deprivation levels. A number of overarching themes emerged: views on social impacts, incorporating social impacts into plans, LTPs, other relevant strategies and joint working. The first two refer to the views of interviewees on the relevance of social impacts and the possibility of incorporating them within LAQM. Interviewees were generally receptive to the idea of social impact and its significance but most had reservations about the possibility of incorporating them. Some stated that LAQM was not an appropriate process to take account of EJ.

The integration with LTPs was considered important as these plans tend to take account of the social needs of a local community. However, the success of integration was mixed. Some unitary authorities had successfully integrated their AQAP and LTP. But District Councils had found it more difficult to work with County Councils. 'Strategies' referred to other local authority policy documents which were considered relevant to EJ. These included Health Impact Assessments, Strategic Environmental Assessments, Sustainability Audits, Community Strategies and work undertaken as part of Local Strategic Partnerships.

Overall the case studies revealed that issues related to EJ are not usually taken into account in the AQAP process. But in some cases progress has been made through integration with LTPs which take greater account of local social issues.

\section{Discussion}

While the research revealed that AQMAs are often in areas of considerable deprivation, this is not specifically taken into account in developing AQAPs or prioritising measures within them. Local authorities follow government guidance and, in the main, do not take account of social data. However, the case study interviews revealed that local authority officers were aware of the level of social deprivation within their area and implicitly considered social impacts when assessing options. The prevailing view regarding the formal use of social data was negative; it was considered as an extra burden given the existing difficulties surrounding the production and implementation of AQAPs. This is not surprising as taking account of social impacts does not feature prominently in current Government guidance.

Public consultation was widely undertaken but it was less clear how the local knowledge gained was used in decision making. Communicating air pollution issues to the public and gathering their local knowledge can be problematic [9]. The types of measures and the way they were described in the AQAPs meant it was very difficult to assess their respective contributions to improving air quality. An analysis of the measures according to their origin and prospect of implementation revealed that their majority were not AQAP specific. This is not necessarily a negative finding; as if AQAPs are developed in conjunction with other local authority initiatives there may be greater potential to address EJ issues. 
The morphology of urban space can have an impact on social deprivation. Space itself can be considered a factor in the geography of poverty and can contribute to persistent poverty [10]. Hence, where appropriate, AQAPs should be integrated with planning, neighbourhood renewal and regeneration initiatives. It would be beneficial to make use of whatever services a LA already has in place that could improve the inclusion of social impacts in decision making. These include community development, neighbourhood renewal and regeneration. A review of LA practices, policies and experiences with the use of social data across departments would help make an informed decision about using such data in AQAPs.

The principles of sustainable development coincide with EJ. At a global scale, local knowledge in conjunction with capital is believed to be a key to sustainable socioeconomic development [11]. In terms of LAQM and action planning the methods used by local authorities to gather this information have not been successful as the results of their efforts are not necessarily used. One problem may be a lack of understanding as to how best to use this information. There is also some scepticism surrounding its usefulness and relevance [12, 13]. Nevertheless it is important that public involvement is promoted. A better practice guide on LAQM consultation has been published providing an indicative guide for LAs [9].

An interesting example of the effect of traffic control measures on air quality and inequality is the London Congestion Charge. This was introduced in February 2003 to alleviate traffic congestion in central London. In a study to investigate the impacts on health and inequality Tonne et al. [14] used two modelled scenarios to isolate the changes in pollution due to traffic flow and speed, assuming meteorology was the same for both periods and no downward trend in emissions as the vehicle fleet was updated. Mortality impacts were estimated in terms of life years gained (LYG) by combining modelled changes in pollution concentration with pollution-mortality data. Population exposures to $\mathrm{PM}_{10}$ and $\mathrm{NO}_{2}$ were analysed by quintile of socio-economic deprivation by overlaying modelled pollution concentrations on census areas of about 1500 population, using the Index of Multiple Deprivation. Modelled concentrations increased with deprivation although this relationship was less marked for $\mathrm{PM}_{10}$ than for $\mathrm{NO}_{2}$. Within the congestion zone and adjacent wards LYG were 183 per 100,000 population compared with 26 across London as a whole. While the least deprived group experienced $0.02 \mathrm{ugm}^{-3}$ and $0.01 \mathrm{ugm}^{-3}$ decreases in $\mathrm{NO}_{2}$ and $\mathrm{PM}_{10}$ respectively, the most deprived groups experienced 0.24 and 0.08 decreases. The authors conclude that the CCS had only a modest impact on concentrations of traffic-related pollutants and life expectancy but had also resulted in a slight reduction in inequalities in exposure to traffic-related pollution and mortality rates.

\section{Conclusions}

In England and Wales air quality management areas tend to cover areas of greater social deprivation. Action plans developed to address poor air quality in 
these areas do provide an opportunity to take account of environmental justice. But evidence suggests that, as this is not explicitly required by Government guidance, to date the opportunity has not been fully taken. It was found that many measures in AQAPs are not specific to air quality and this holds out the potential for integration of air quality measures with other local strategies, most notable local transport plans, but also strategies relating to planning. This may provide a better opportunity to take account of environmental justice while improving air quality. Although not intended principally to improve air quality or address environmental inequality, the London Congestion Charge provides initial evidence of the potential of this type of measure.

\section{References}

[1] Bullard, B., Dismantling environmental racism in the USA. Local Environment, 4, pp. 5-19, 1999.

[2] Walker, G., Fairburn, J., Graham, S. \& Gordon, M., Environmental quality, R\&D technical report E2-067/1/TR. Environment Agency: Bristol, 2003.

[3] O’Neill, M. S., Jerrett, M., Kawachi, I., Levy, J. I., Cohen, A. J., Gouveia, N., Wilkinson, P., Fletcher, T., Cifuentes, L. \& Schwartz, J., Health, Wealth and Air Pollution: Advancing Theory and Methods. Environ Health Perspect, 111(16), pp. 1861-1870, 2003.

[4] Laurent, O., Bard, D., Filleul, L. \& Segala, C., Effect of socioeconomic status on the relationship between atmospheric pollution and mortality. $J$ Epidemiol Community Health, 61(8), pp. 665-675, 2007.

[5] H M Government Environment Act 1995, Chapter 25. London: The Stationery Office, 1995.

[6] Longhurst, J. W. S., Irwin, J. G., Chatterton, T. J., Hayes, E. T., Leksmono, N. S. \& Symons, J. K., A critical review of, and commentary on, the development of an effects based air quality management regime. Atmos. Environ., in press.

[7] Gegisian, I., Assessing the contribution of local air quality management to environmental justice in England and Wales. $\mathrm{PhD}$ thesis, University of the West of England, 2007.

[8] ODPM, The English Index of Deprivation 2004. Wetherby: ODPM Publications, 2004.

[9] University of the West of England, Air Quality Review and Assessment Helpdesk.

http://www.uwe.ac.uk/aqm/files/Steps_to_Better_Practice_Guidance_on_L AQM_Consultation.pdf

[10] Vaughan, L., Clark, D. L. C., Sahbaz, O \& Hallay, M., Space and exclusion: does urban morphology play a part in social deprivation. Area, 37, pp. 402-412, 2005.

[11] Corburn, J., Bringing local knowledge into environmental decision making - improving urban planning in communities at risk. Journal of Planning Education and Research, 22, pp. 420-433, 2003. 
[12] Petts, J. \& Brooks, C., Expert conceptualisations of the role of lay knowledge in environmental decision making; challenges for deliberative democracy. Environment and Planning A, 38, pp.1045-1059, 2006.

[13] Cinderby, S. \& Forrester, J., Facilitating the local governance of air pollution using GIS for participation. Applied Geography, 25, pp. 143-158, 2005.

[14] Tonne, C., Beevers, S., Armstrong, B.G., Kelly, F. \& Wilkinson, P., Air pollution and mortality benefits of the London Congestion Charge: spatial and socioeconomic inequalities. Occup. Environ. Med, 2008. http://oem.bmj.com/cgi/content/zabstract/oem.2007.036533v1 